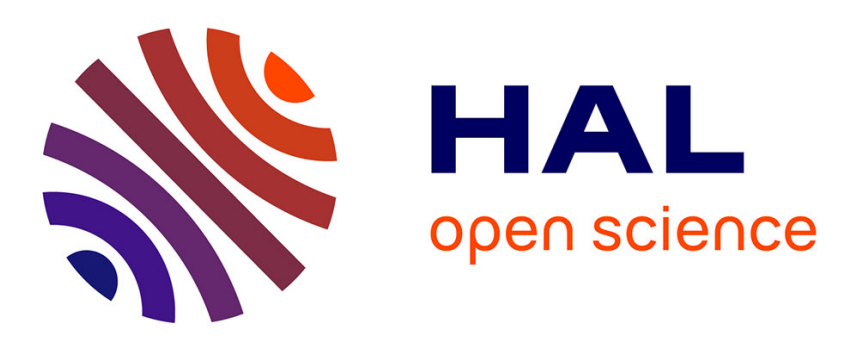

\title{
Understanding of carbon-based supercapacitors ageing mechanisms by electrochemical and analytical methods
}

Yinghui Liu, Benoît Soucaze-Guillous, Pierre-Louis Taberna, Patrice Simon

\section{To cite this version:}

Yinghui Liu, Benoît Soucaze-Guillous, Pierre-Louis Taberna, Patrice Simon. Understanding of carbonbased supercapacitors ageing mechanisms by electrochemical and analytical methods. Journal of Power Sources, 2017, 366, pp.123-130. 10.1016/j.jpowsour.2017.08.104 . hal-01687184

\section{HAL Id: hal-01687184 https://hal.science/hal-01687184}

Submitted on 18 Jan 2018

HAL is a multi-disciplinary open access archive for the deposit and dissemination of scientific research documents, whether they are published or not. The documents may come from teaching and research institutions in France or abroad, or from public or private research centers.
L'archive ouverte pluridisciplinaire HAL, est destinée au dépôt et à la diffusion de documents scientifiques de niveau recherche, publiés ou non, émanant des établissements d'enseignement et de recherche français ou étrangers, des laboratoires publics ou privés. 


\section{Open Archive TOULOUSE Archive Ouverte (OATAO)}

OATAO is an open access repository that collects the work of Toulouse researchers and makes it freely available over the web where possible.

This is an author-deposited version published in : http://oatao.univ-toulouse.fr/ Eprints ID : 19356

To link to this article :

URL : http://dx.doi.org/10.1016/j.jpowsour.2017.08.104

\section{To cite this version :}

Liu, Yinghui and Soucaze-Guillous, Benoît and Taberna, Pierre-

Louis and Simon, Patrice Understanding of carbon-based supercapacitors ageing mechanisms by electrochemical and analytical methods. (2017) Journal of Power Sources, vol. 366. pp. 123-130. ISSN 0378-7753

Any correspondence concerning this service should be sent to the repository administrator: staff-oatao@ listes-diff.inp-toulouse.fr 


\title{
Understanding of carbon-based supercapacitors ageing mechanisms by electrochemical and analytical methods
}

\author{
Yinghui Liu ${ }^{\text {a, b, c }}$, Benoît Soucaze-Guillous ${ }^{\text {a }}$, Pierre-Louis Taberna ${ }^{\text {b, c }}$, Patrice Simon ${ }^{\text {b, * }}$ \\ a Technocentre Renault, 1 avenue du Golf, API: TCR RUC 1 82, F-78084, Guyancourt, France \\ b CIRIMAT, Université de Toulouse, CNRS, INPT, UPS, 118 route de Narbonne, 31062, Toulouse, France \\ ${ }^{\mathrm{c}}$ Réseau sur le Stockage Electrochimique de l'Energie (RS2E, FR CNRS 3459), France
}

\section{H I G H L I G H T S}

- Ageing of carbon based supercapacitors is studied by various analytical methods.

- Two ageing mechanisms are observed depending on varied activated carbon species.

- Supercapacitors based on carbon A aged with a continuous material modification.

- A passive layer formed on carbon B during the ageing of the supercapacitor.

\section{Keywords:}

Supercapacitor ageing

Electrochemical characterization

Diffusion coefficient

Activated carbon corrosion

Ageing mechanism

\begin{abstract}
A B S T R A C T
In order to shed light on ageing mechanisms of Electrochemical Double Layer Capacitor (EDLC), two kinds of activated carbons are studied in tetraethyl ammonium tetrafluoroborate $\left(\mathrm{Et}_{4} \mathrm{NBF}_{4}\right)$ in acetonitrile. In floating mode, it turns out that two different ageing mechanisms are observed, depending on the activated carbon electrode materials used. On one hand, carbon A exhibits a continuous capacitance and series resistance fall-off; on the other hand, for carbon B, only the series resistance degrades after ageing while the capacitance keeps unchanged. Additional electrochemical characterizations (Electrochemical Impedance Spectroscopy - EIS - and diffusion coefficient calculations) were carried out showing that carbon A's ageing behavior is suspected to be primarily related to the carbon degradation while for carbon B a passivation occurs leading to the formation of a Solid Electrolyte Interphase-Like (SEI-L) film. These hypotheses are supported by TG-IR and Raman spectroscopy analysis. The outcome forms the latter is an increase of carbon defects on carbon A on positive electrode.
\end{abstract}

\section{Introduction}

Energy is one of the main topics of discussion and research in today's society. With shortages in petroleum reserves and worries about the effects of greenhouse gas emissions, there has been a considerable amount of effort put into the research, development, and deployment of renewable energy sources. For this reason, research into devices for Electrochemical Energy Storage (EES) has been a major topic of the research community during the past decade. However, classical battery and capacitor systems have limits for the amount of energy they are capable of storing and limitations for the rates at which they can deliver that energy [1].

* Corresponding author

E-mail address: simon@chimie.ups-tlse.fr (P. Simon).
Supercapacitors (SCs), introduced in 1957 by Howard Becker of "American General Electric", have an intermediate energy-power yield compared to capacitors and batteries [2]. SCs are capable of storing larger amounts of energy than traditional capacitors, but SCs can still deliver this energy at high rates (high power), but only for a short time [3]. Based off these characteristics, the main applications that SCs that have drawn interest for are use in handheld electronic devices, transportation, and the electric power grid [1] [4]. Nowadays, most studies into SCs are concerning materials for pseudo-capacitors [5], hybrid capacitors [6] [7] [8], as well as SCs with high capacitance due to studies into the carbon's pore sizes and distributions [9] for the purpose of increasing the energy density of SCs. Despite all these efforts to improve the performance of new materials for SCs, activated carbon-based SCs called Electrochemical Double Layer Capacitors are still the only practical candidates for industrial SC applications because of their relative 
low cost and high cyclability. However, the nature of the parasitic chemical reactions that occur between activated carbon electrodes and organic electrolytes is still unclear. Understanding these parasitic chemical reactions (called ageing mechanisms in the following parts) is important for industrial applications for safety and security reasons. Also, knowledge of these reactions is important for further optimization of the performance of SCs.

Until now, only few papers have concentrated their efforts into investigating the ageing mechanisms of activated carbon based SCs in acetonitrile-based electrolyte under constant potential [10] [11] [12] [13]. Among them, Azaïs et al. proposed an understanding of ageing mechanism in 2007 [10]. By using two different activated carbons, they suggested that the ageing of SCs is closely related to the decomposition of the organic electrolyte at the active surfaces of the carbon. Azaïs et al. also purposed that activated carbons should have small amounts of surface functionalities, suitable pore size distributions, and an absence of moisture to ensure stable longterm performance [10]. Zhu et al. further investigated the ageing mechanisms of SC materials [11]. Using acetonitrile-based electrolyte under $2.9 \mathrm{~V}$ for 45 days, they found that the positive electrode (mentioned in their text as anode) suffers more from ageing effects. Through the use of nitrogen adsorption-desorption analysis, they showed that only pores between $0.5 \mathrm{~nm}$ and $0.8 \mathrm{~nm}$ are affected by ageing. Also, from Element Analysis, X-ray Photoelectron Spectroscopy (XPS) and Infrared (IR) measurements, they found some nitrogen-containing species on the carbon following ageing. These species can be pyridine moieties $(\mathrm{C}=\mathrm{N}-\mathrm{C})$, amines ( $\mathrm{C}$ $\mathrm{NH}_{2}$ ), polyacetonitrile $(-\mathrm{C}=\mathrm{N}-)_{\mathrm{n}}$ and amides, which they said are most likely due to cathodic $(-)$ and anodic $(+)$ polymerization reactions of acetonitrile. From Raman spectroscopy, they observed decrease of the $G$ band $\left(1596 \mathrm{~cm}^{-1}\right)$ and increase of the $D_{3}$ band $\left(\sim 1500 \mathrm{~cm}^{-1}\right)$. Zhu et al. considered that the decrease in the $\mathrm{G}$ band is related to the loss of ideal graphitic lattices in the activated carbon and the increase of the $\mathrm{D}_{3}$ band concerns increases of nongraphitic moieties (amorphous carbon). Thus, according to the results of Zhu et al., the disorder of the activated carbon structure increases after ageing. A few years later, A. M. Bittner et al. [12] completed the previous works by studying the ageing of a commercial SC (2.5 V 200 F Epcos AG). Their results proved to be the same as [11]. According to their results, the presence of $\mathrm{BF}_{4}^{-}$ together with $\mathrm{H}^{+}$are keys to the polymerization of acetonitrile, which ultimately contributes to the failure of the supercapacitor.

Additionally, P. Kurzweil and M. Chwistek put their efforts into electrolyte and gas analysis. In an acetonitrile/Et $\mathrm{NBF}_{4}$ system, they found heterocyclic compounds (such as pyrazines) and cyclic siloxane in the electrolyte after electrochemical ageing. Also, the electrolyte became brown in color after electrochemical ageing. They proposed that the aged electrolyte should consist of acetamide, organic acids, fluoroacetic acid derivates and polymer products. Concerning analysis of the gas that was evolved during ageing, hydrogen was detected during ageing which was generated by electrolysis of residual water or by the fluorination of carboxylic acids [13].

Another aspect of ageing in SCs is related to the surface functional groups of activated carbons. A. Yoshida et al. [18] proved that the acidic functional groups had a negative influence on the lifetime of SCs. Yoshida used phenolic resin-based novolac fibers (ACF) that were heat treated for different times or at different temperatures. They proved that the leakage current can be reduced when the amount of the ACF's acidic surface functional groups are reduced. The acidic functional groups, like alcohol, ketone, carboxyl and ester groups on ACF behave as active sites for the acceleration of electrochemical oxidation or reduction of ACF during polarization. Furthermore, heat treatments in $\mathrm{N}_{2}$ atmosphere decreased the amount of acidic surface functional groups in ACF which resulted in the suppression of electrochemical interactions of the ACF with the electrolyte, which in turn decreases the SCs' leakage current [18].

In summary, many different characterization techniques have been employed in different studies to characterize the ageing behavior of activated carbons in non-aqueous electrolytes. In this paper, we use the combination of various electrochemical (galvanostatic cycling and impedance spectroscopy) and analytical (Raman, Infrared spectroscopies) and materials characterization (TGA) methods to study the ageing mechanism of two different carbons during constant potential (floating) experiments. This approach gives a holistic picture of two different types of ageing mechanisms for activated carbon-based supercapacitors.

\section{Experimental}

\subsection{Electrochemical characterizations}

Two different kinds of activated carbon, $\mathrm{A}$ and $\mathrm{B}$, were tested in this study. A is a YP-50F activated carbon from the Kuraray company, a porous carbon used for supercapacitor applications; it has been used as a reference in our ageing tests. B is a porous carbon used for water purification applications. Table 1 gives the characteristics of $\mathrm{A}$ and $\mathrm{B}$. Electrodes made from activated carbon $\mathrm{A}$ contained $95 \mathrm{wt} \%$ of activated carbon $\mathrm{A}$ and $5 \mathrm{wt} \%$ of PTFE as binder, while the electrodes made from activated carbon B contained $80 \mathrm{wt}$ $\%$ of activated carbon B, 5 wt\% of PTFE and $15 \mathrm{wt} \%$ of carbon black (to compensate for the poor conductivity of activated carbon B). The electrodes were rolled to thicknesses of $\sim 300 \mu \mathrm{m}$ with mass loadings of $15 \mathrm{mg} \mathrm{cm}^{-2}$. Activated carbons A and B were used as electrodes for 2-electrode symmetric supercapacitors, which will be referred to as supercapacitor A (SC A) and supercapacitor B (SC B). Supercapacitor cells were assembled using a Swagelok cell (Swagelok ${ }^{\mathbb{R}}$ ) and each cell used platinum disks for current collectors and a cellulose membrane as the separator. The electrolyte used for each cell was $1.5 \mathrm{M} \mathrm{Et}_{4} \mathrm{NBF}_{4}\left(99 \%\right.$, ACROS Organics $\left.{ }^{\mathrm{TM}}\right)$ in acetonitrile (HPLC Gradient, ACROS Organics ${ }^{\mathrm{TM}}$ ). Three-electrode cells were used in order to have a sufficient reservoir of electrolyte. Before assembly, activated carbon electrodes were dried in an oven at $120^{\circ} \mathrm{C}$ under vacuum for $12 \mathrm{~h}$. All supercapacitor cells were assembled in a Glovebox (MBRAUN, UNIlab Pro Glove Box Workstation) with controlled atmosphere $\left(<1 \mathrm{ppm} \mathrm{O}_{2}\right)$. All supercapacitor cells were tested at room temperature using a VMP3 potentiostat (Biologic, USA.)

These SCs were first characterized electrochemically by Galvanostatic Cycling (GC), Cyclic Voltammetry (CV) and Electrochemical Impedance Spectroscopy (EIS) to determine their initial electrochemical characteristics. After the initial characterization, all SC cells were subjected to an accelerated electrochemical ageing process. In this process one ageing cycle consisted of $12 \mathrm{~h}$ of a potensiostatic hold, called "floating", followed by 6 galvanostatic cycles (Supplementary information: Fig. A.1). The capacitance and the internal resistance were measured from the discharge portion of the $6^{\text {th }}$ galvanostatic cycles. The value of the internal resistance is taken at $\Delta \mathrm{t}=\mathrm{t}_{0}-\mathrm{t}=0.0008 \mathrm{~s}(\Delta \mathrm{f}=1250 \mathrm{~Hz})$, where $\mathrm{t}=\mathrm{t}_{0}$ at $\mathrm{E}=2.5 \mathrm{~V}$. The leakage current is the last point of the current collected during the floating process, once a steady-state was reached. The integrated charge during ageing is defined by Eq. (A.1) (Supplementary information, Eq. (A.1)).

$Q_{i}=\int_{0}^{t} I d t$

We set an increase of $500 \%$ for the internal resistance or a loss of $50 \%$ of the initial capacitance as the criteria for the SCs' end of life. 
After ageing, the SCs are tested again by GC, CV and EIS to compare their behavior before and after ageing.

Another important electrochemical factor, the Diffusion Coefficient, is also compared here. The calculation of the Diffusion Coefficient for each battery system is calculated using the Huggins' Equation (Equation (2)). Parameters for the Huggins' Equation are traditionally determined in batteries by using the Galvanostatic Intermittent Titration Method (GITT) [21].

$D(\text { ion })_{\text {battery }}=\frac{4}{\pi} \times\left(\frac{V_{M}}{z F S}\right)^{2} \times\left(\frac{I \cdot\left(\frac{d E}{d \delta}\right)}{d E / d \sqrt{t}}\right)^{2}$

Here, $\mathrm{V}_{\mathrm{M}}$ is the molar volume, $\mathrm{z}$ the charge carried by the electroactive species, $\mathrm{F}$ the Faraday constant, $\delta$ the stoichiometric parameter, E the applied voltage, I the applied current and $\mathrm{S}$ the surface area. In Huggins' Equation, $\left(\frac{V_{M}}{z F S}\right)$ corresponds to diffusion distance, and in the case of supercapacitors this part can be calculated by $\left(\frac{V_{\text {sphere }}}{S_{\text {sphere }}}\right)=\left(\frac{\frac{4}{3} \pi R_{S}^{3}}{4 \pi R_{S}^{2}}\right)=\left(\frac{R_{S}}{3}\right)$, where $R_{S}$ is the radius of spherical particles. Since $Q=C \cdot \Delta E$, then, $I \cdot\left(\frac{d E}{d \delta}\right)=I / C$ in the case of SCs. Consequently, the Diffusion Coefficient equation for supercapacitor becomes:

$D(\text { ion })_{S C}=\frac{4}{\pi} \times\left(\frac{R_{S}}{3}\right)^{2} \times\left(\frac{I / C}{d E / d \sqrt{t}}\right)^{2}$

The capacitance here is calculated in the same way as before. The current is then the current applied during the discharge portion of the galvanostatic cycling process, which is equal to 0.005 A. The radius, $R_{S}$, used for the Diffusion Coefficient calculation is an average value of 50 radius measurements ( 5 different SEM images, 10 particles radius measurements on each image). The part, $d E / d \sqrt{t}$ is calculated from the diffusion region of the galvanostatic cycling corresponding to the intermediate part of the discharge curves between the ohmic drop and the capacitive part.

\subsection{Material characterizations}

After ageing, the SCs were opened, disassembled, and each element of the SCs was separated. Each electrode was washed three times ( $1 \mathrm{~h}$ per washing cycle) using acetonitrile (99.9\%, Extra Dry, AcroSeal $^{\mathrm{TM}}$, ACROS Organics $\left.{ }^{\mathrm{TM}}\right)$. Afterwards, all electrodes were dried for $1 \mathrm{~h}$ at $120{ }^{\circ} \mathrm{C}$ under vacuum before being tested by following methods.
2.2.1. Thermogravimetric analysis (TGA) coupled with Infrared (FTIR) analysis

IR coupled TGA was done using a Thermo-Scientific TGA-IR Module, equipped with a $\mathrm{KBr}$ window. This module enables a SETSYS EVOLUTION TGA machine (from SETARAM) to be connected to a Nicolet is10 FT-IR spectrometer. For TGA the working atmosphere is $80 \% \mathrm{Ar}$ and $20 \% \mathrm{O}_{2}$, with a gas flux of $40 \mathrm{~mL} \mathrm{~min}{ }^{-1}$. The temperature analysis range was from $20{ }^{\circ} \mathrm{C}$ to $1000{ }^{\circ} \mathrm{C}$, with a heating rate of $5{ }^{\circ} \mathrm{C} \mathrm{min}^{-1}$. FT-IR measurements were performed every minute (every $5^{\circ} \mathrm{C}$ ).

\subsubsection{Raman spectroscopy}

Raman Spectroscopy using a Labram HR 800 Yvon Jobin from HORIBA YVON JOBIN, was also used in the physical characterization of the SC electrodes before and after ageing. Raman measurements were done using a green laser with $\lambda=532 \mathrm{~nm}$, a $600 \mathrm{tr} \mathrm{mm}^{-1}$ grating and a $100 \times$ objective.

\section{Results and discussion}

\subsection{Electrochemical characterizations}

Figs. 1 and 2 present the evolution of the different electrochemical parameters that were monitored during the ageing of SC A and SC B. The two SCs suffered from the ageing process in different ways, as can be seen by comparing Figs. 1 and 2 .

After ageing, the capacitance and the internal resistance of SC A degrade almost linearly (Fig. 1a). The leakage current (Ileakage) (Fig. 1b) also presents a peak at the very beginning of the ageing process which is accompanied by a sharp increase in the integrated charge $\left(\mathrm{Q}_{\mathrm{i}}\right)$. This phenomenon is probably linked to the consumption of impurities. This period in the ageing process occurs during the drop in capacitance seen at the very beginning ( $1^{\text {st }}$ ageing cycle to $10^{\text {th }}$ ageing cycle). After the initial peak, the leakage current stays close to zero. Consequently, the integrated charge increases slowly with a slope much less important than before. After ageing, the shape of the galvanostatic charge discharge plot shrinks considerably compared to the cycles performed before ageing (Fig. 1c). The impedance spectra (Fig. 1d) shows that the high frequency resistance at $Z "=0$, that is ESR (Equivalent series resistance) changed from $0.9 \Omega \mathrm{cm}^{2}$ to $2.9 \Omega \mathrm{cm}^{2}$ following ageing. The increase of ESR indicates changes in the total cell resistance from the modification of the electrical percolation network in the electrode. The EIS plot shows as well the presence of a small RC loop at high frequency, initially not present in the system, reaching a diameter value of $7.3 \Omega \mathrm{cm}^{2}$ following the ageing process. The latter may have several origins, such as changes in the contact interface between the electrode film (activated carbon) and the current collector [22] and/ or the formation of a passive layer on the porous carbon surface due to electrolyte oxidation/reduction; carbon surface degradation

Table 1

Characteristics of carbon A and carbon B.

\begin{tabular}{|c|c|c|c|}
\hline Product name & & A (YP-50F) & $\mathrm{B}$ \\
\hline Specific area $\left(\mathrm{m}^{2} \mathrm{~g}^{-1}\right)^{\mathrm{a}}$ & & 1732 & 1297 \\
\hline \multirow[t]{2}{*}{ Porosity type } & Micropore (\%) & 92 & 72 \\
\hline & Mesopore (\%) & 8 & 28 \\
\hline Total volume $\left(\operatorname{cc~g~nm}{ }^{-1}\right)^{\mathrm{a}}$ & & 0.791 & 0.755 \\
\hline Microporous volume $\left(\mathrm{cc} \mathrm{g} \mathrm{nm}^{-1}\right)^{\mathrm{a}}$ & & 0.726 & 0.543 \\
\hline Mesoporous volume $\left(\mathrm{cc} \mathrm{g} \mathrm{nm}{ }^{-1}\right)^{\mathrm{a}}$ & & 0.065 & 0.213 \\
\hline Pore's medium diameter $(\mathrm{nm})^{\mathrm{a}}$ & & 0.76 & 1.06 \\
\hline Water $(w t \%)^{b}$ & & 3 & 3 \\
\hline Ash $(w t \%)^{\mathrm{b}}$ & & $<1$ & 10 \\
\hline
\end{tabular}

a Measured information.

b Supplier's datasheet. 
(oxidation) would also lead to increase such kind of behavior. As a result, the capacitive behavior (increase of the imaginary part of the impedance) is shifted to lower frequencies and higher resistance, as can be seen in Fig. 1d.

In contrast to SC A, the capacitance for SC B stays almost the same throughout the ageing process. However, the series resistance increases sharply starting at the $45^{\text {th }}$ ageing cycle (Fig. 2a). There are differences in the leakage current profile of SC B as well. The leakage current of SC B increases quickly from the $1^{\text {st }}$ ageing cycle until $45^{\text {th }}$ ageing cycle, then it decreases until last ageing cycle. Consequently, the integrated charge plot has a steep slope near the $45^{\text {th }}$ ageing cycle (Fig. 2b). A significant ohmic drop is observable after ageing on the galvanostatic plots (Fig. 2c); however, the slope of the capacitive region of the plot does not change, thus confirming that the capacitance of SC B stays the same during the ageing and only the internal resistance increases. More information can be found by comparing the impedance spectra of SC B from before and after ageing. Following ageing, ESR for SC B is equal to $1 \Omega \mathrm{cm}^{2}$, which is the same value obtained before ageing. However, a large high frequency RC loop of $84 \Omega \mathrm{cm}^{2}$ diameter appeared after ageing. The latter is much larger than was observed for SC A after ageing. The internal resistance is the sum of ESR and RC loop. Consequently, the increase of the internal resistance is due to the increase of RC loop. As for the capacitive part, it is consistent with the results discussed earlier (Fig. 2d).

By using Equation (3) the diffusion coefficients, $D_{\text {ion }}$, of two the SC systems can be calculated. $D_{\text {ion }}$ for SCs A and B are plotted versus integrated charge in Fig. 3 to compare ion diffusion in the two different SC systems. For the SC A, $D_{\text {ion }}$ stays almost constant until around $200 \mathrm{~mA} \mathrm{~h}\left(200^{\text {th }}\right.$ ageing cycle, according to Fig. $\left.1 \mathrm{~b}\right)$ then it decreases quickly. This means that the degradation of materials begins near the $200^{\text {th }}$ ageing cycle and the degradation of SC A becomes irreversible following this point. The change in $\mathrm{D}_{\text {ion }}$ during ageing for SC B is completely different from the behavior seen for SC A. $D_{\text {ion }}$ for SC B decreases continuously from the start of the ageing process. From this result, since SC B undergoes a continuous ageing leading to a decrease of the diffusion coefficient, one would ascribe this behavior to surface functional groups at the carbon surface. However, according to IsoElectric Point (IEP) analysis, $B$ has a higher IPE than A (Supplementary information Fig. A.2) which means that less acidic functions are present at the carbon B surface. This point is not consistent with Yoshida et al.'s observations who correlated important ageing together with the presence of acidic group on the carbon surface [18]. Thus, the apparent continuous ageing of carbon $B$ should be driven by another parameter.

To conclude these previous results, there were two different ageing mechanisms for the two different types of activated carbons used in SCs A and B. For SC A, ageing occurred slowly and continuously, with degradation seen in both the capacitance and the internal resistance, beginning near the $200^{\text {th }}$ ageing cycle. For SC B, degradation begins near the $45^{\text {th }}$ ageing cycle where $\mathrm{I}_{\text {leakage }}$ reaches its maximum, but only the internal resistance shows any notable changes during cycling while the capacitance is kept constant. From the EIS plot, a significant RC loop appeared after ageing. Additionally, the ion diffusion coefficient $\mathrm{D}_{\text {ion }}$ for SC B decreases continuously all along the ageing cycle. At this point, one can assume the formation of a passive layer on the activated carbon $B$ during ageing instead of degradation of the activated carbon. This passive layer should be ionically conductive since the capacitance of SC B did not decrease with ageing, but the passive layer should electronically resistive which would explain the presence of the high frequency RC loop following ageing, leading to a resistance increase. From these characteristics, it can be seen as a Solid Electrolyte Interphase-Like film at the surface of the carbon $\mathrm{B}$.

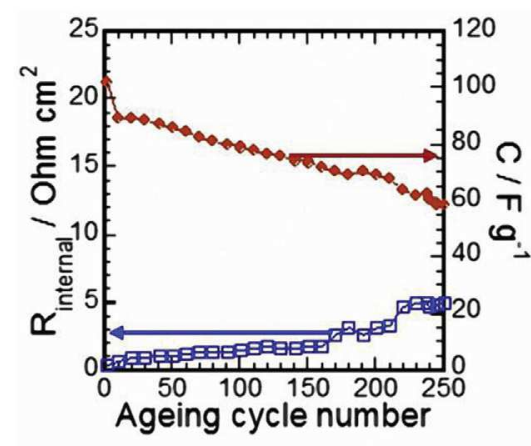

(a)

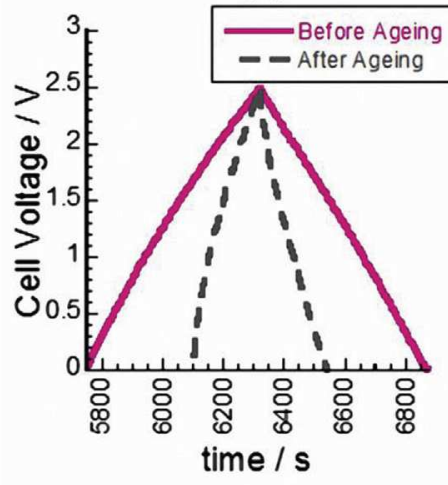

(c)

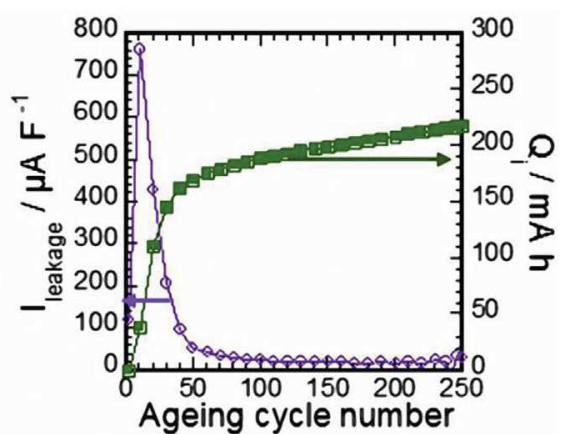

(b)

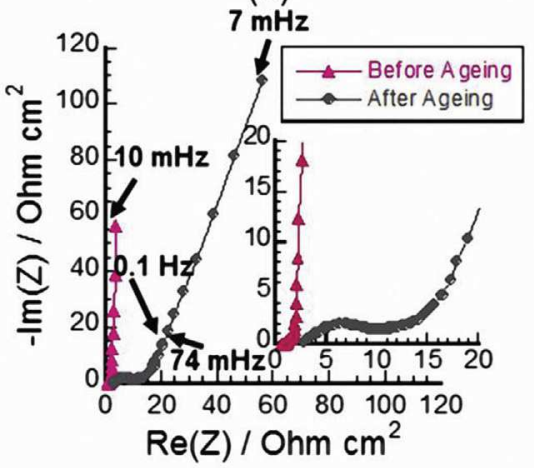

(d)

Fig. 1. Electrochemical Characterization of SC A: (a) evolution of the internal resistance and capacitance during ageing; (b) evolution of the leakage current and the integrated charge during ageing; (c) comparison of the GC before and after ageing; (d) comparison of the EIS before and after ageing. 


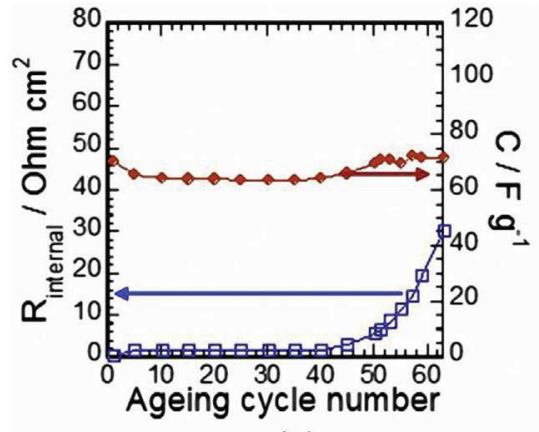

(a)

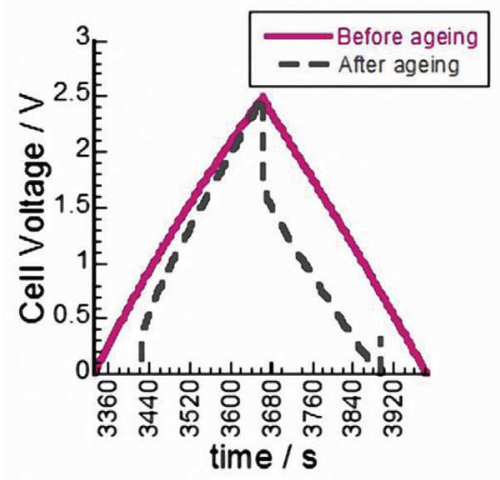

(c)

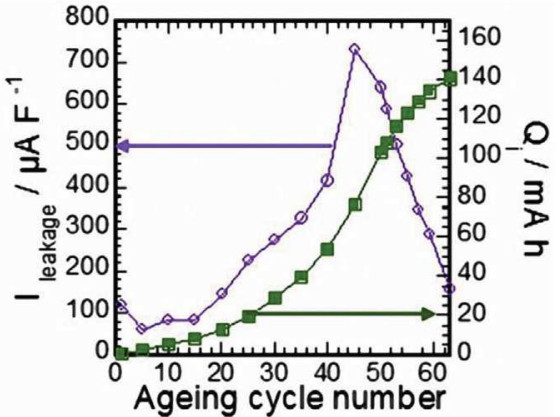

(b)

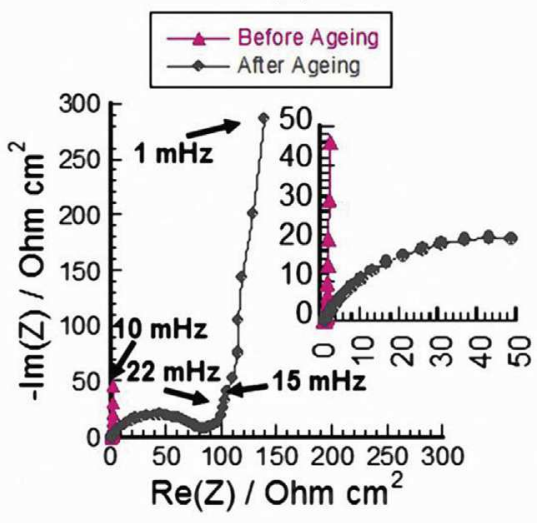

(d)

Fig. 2. Electrochemical Characterizations of SC B: (a) evolution of the internal resistance and the capacitance during ageing; (b)evolution of the leakage current and the integrated charge during the ageing process; (c) comparison of the GC before and after ageing; (d) comparison of the EIS before and after ageing.

\subsection{Materials characterizations}

Coupling these results together with physical characterizations of the electrode materials from before and after electrochemical ageing could provide more insight into the proposed ageing mechanisms for SCs A and B. A series of TGA measurements showed very few differences between the initial electrodes and negative electrodes after the ageing process (see Supplementary information Fig. A.3 and Fig. A.4). According to the literature, negative electrodes suffer less from ageing than positive electrodes [10] [11] [12] [13]. For this reason, only positive electrodes and initial electrodes were analyzed and compared by TG-IR.

Fig. 4 illustrates results of positive electrodes after ageing for SC A (Fig. 4a and b) and for SC B (Fig. 4c and d). The common

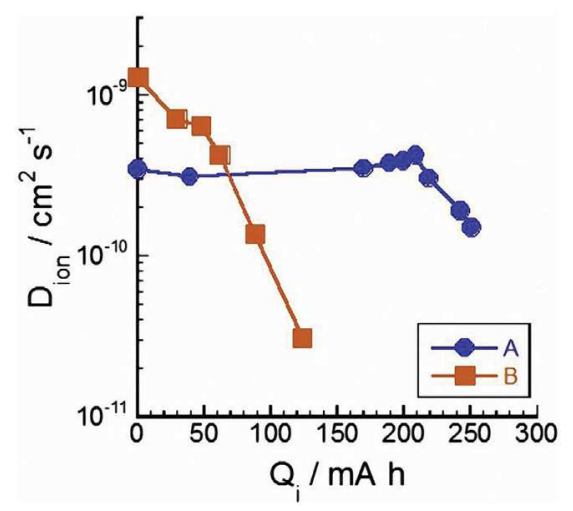

Fig. 3. Evolution of diffusion coefficients versus integrated charge. characteristic observed for both the initial electrodes and the aged positive electrodes is that they are all oxidized into $\mathrm{CO}_{2}$ under the $\mathrm{O}_{2}$ environment and no other gasses are detected. This means that the activated carbons' chemical composition doesn't change during ageing. For every electrode material that went through the aging process, the carbons react with $\mathrm{O}_{2}$ at lower temperatures, which could be explained by an increased disorder of activated carbon due to oxidation. To be more specific, for SC A, the aged positive electrode reacts with $\mathrm{O}_{2}$ at two different temperatures: one major part at $450{ }^{\circ} \mathrm{C}$ and one minor part at $300{ }^{\circ} \mathrm{C}$ (demonstrated by the dTG and Integrated Infrared $\mathrm{CO}_{2}$ Peak Area). Thus, not only did the carbon became globally more disordered, but there was also the modification of a minor part of the activated carbon during ageing which resulted in some of the carbon having more defects (Fig. 4a and $\mathrm{b}$ ). A similar process also seems to have happened to the aged positive electrode of SC B. However, one difference is that the electrode from SC B still presents a minor peak around $600{ }^{\circ} \mathrm{C}$ in the initial electrode and the aged positive electrode. Compared to the initial electrode, the presence of this minor peak - slightly lower in terms of temperature - shows that a part of the carbon structure was not affected by the ageing process (Fig. $4 \mathrm{c}$ and $\mathrm{d}$ ).

Even though similar things happened to electrodes from both SC $A$ and SC B, TGA-IR results bring interesting information. The main decomposition peak decreases by $70{ }^{\circ} \mathrm{C}$ in the case of SC B, compared to $130{ }^{\circ} \mathrm{C}$ for SC A (initial electrode TG-IR graphs in Supplementary information Fig. A.3). Also, in terms of TG weight loss, the new peak seen at $\sim 300{ }^{\circ} \mathrm{C}$ accounts for $15 \%$ of the weight loss for SC B, while the same peak accounts for around $20 \%$ weight loss for SC A. All this information proves that SC A suffered more from ageing than SC B.

Fig. 5 presents the Raman spectra of the electrode materials of 
SC A and SC B. In Fig. 5a, the aged positive electrode of SC A has a more prominent $D G$ peak overlap phenomenon than that of the initial electrode and the aged negative electrode. According to [23], the $D$ and $G$ peaks' overlap is more important when the crystallite sizes $L_{a}$ decreases, $L_{a}$ being the crystallite size of the organized graphite. Thus, the crystallite sizes $\mathrm{L}_{\mathrm{a}}$ should be smaller in the aged positive electrode. Whereas, this is not the case in SC B where the overlap is the same for both the aged and initial electrodes.

Cançado et al. [23] mentions that the loss of sharpness of the second order features (a broad feature from $\sim 2300$ to $\sim 3200 \mathrm{~cm}^{-1}$ modulated by the 2D, D $+\mathrm{D}^{\prime}$ and $2 \mathrm{D}^{\prime}$, see Fig. 5 zoom 2 of (a) and (b)) can be obtained from $L_{D}=2 \mathrm{~nm}$, where $L_{D}$ is the distance between defects which is measured by Scanning Tunneling Microscopy (STM). Our Raman spectra all contain broad second order features and so we can speculate that our sample initially had a $\mathrm{L}_{\mathrm{D}}<2 \mathrm{~nm}$.

Apart from the D G peak overlap observation, it is also important to analyze the differences in full width at half-maximum for the spectra of each material. The intensity represents the phonon modes/molecular vibration involved in most resonant Raman processes, the full width at half-maximum, denoted as FWHM or $\Gamma$, is a measure of structured disorder [24]. Cançado et al. [23] observed that $\Gamma_{\mathrm{D}}$ and $\Gamma_{\mathrm{G}}$ increase as the $\mathrm{L}_{\mathrm{D}}$ decreases (defects increase). In our case, $\Gamma_{D}$ and $\Gamma_{G}$ of SC A's aged positive electrode are larger than those of both the aged negative electrode and the initial electrodes $\left(\Delta \Gamma_{\mathrm{D}}=+30 \mathrm{~cm}^{-1}\right.$ and $\left.\Delta \Gamma_{\mathrm{G}}=+40 \mathrm{~cm}^{-1}\right)$. But for SC B, only slight differences of $\Gamma_{\mathrm{D}}$ are observed between the aged electrodes and the initial electrodes $\left(\Delta \Gamma_{D}=+10 \mathrm{~cm}^{-1}\right)$ (Supplementary information Table A.1).

To summarize the Raman characterization, we have an increase of the overlap phenomenon in the case of SC A's aged positive electrode that proves that the crystallite size decreases in the positive electrode during the ageing process. In addition to this, $\Gamma_{D}$ and $\Gamma_{G}$ for SC A's aged positive electrode show more drastic changes, which means the density of defects increases in the positive electrode of SC A following ageing. Defects occurring at the positive electrodes (undergoing possible oxidation) can be related to the size of nanocrystallite, point defects in the $\mathrm{sp}^{2}$ carbon lattice and may also lead to the creation of some $\mathrm{sp}^{3}$ sites by the attachment of $\mathrm{O}, \mathrm{F}$, or $\mathrm{H}$ functionalities at different carbon sites.

For SC B, only small changes in $\mathrm{I}_{\mathrm{D}} / \mathrm{I}_{\mathrm{G}}$ and $\Gamma_{\mathrm{D}}$ were observed. This is also proof that SC B suffered from the ageing process, but the

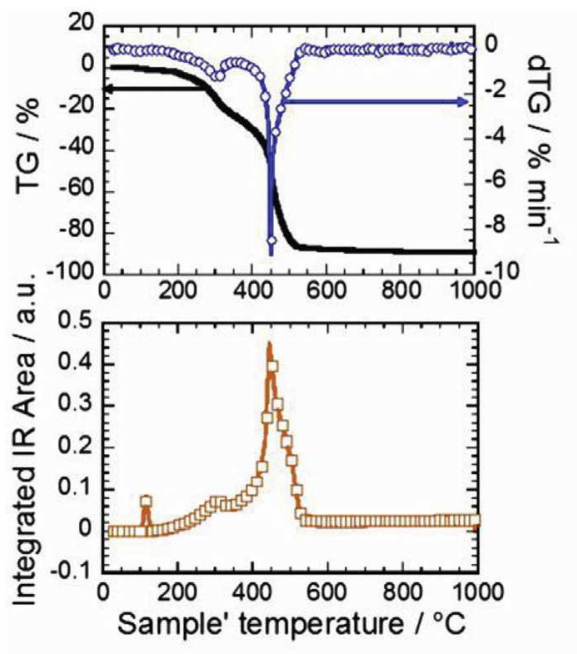

(a)

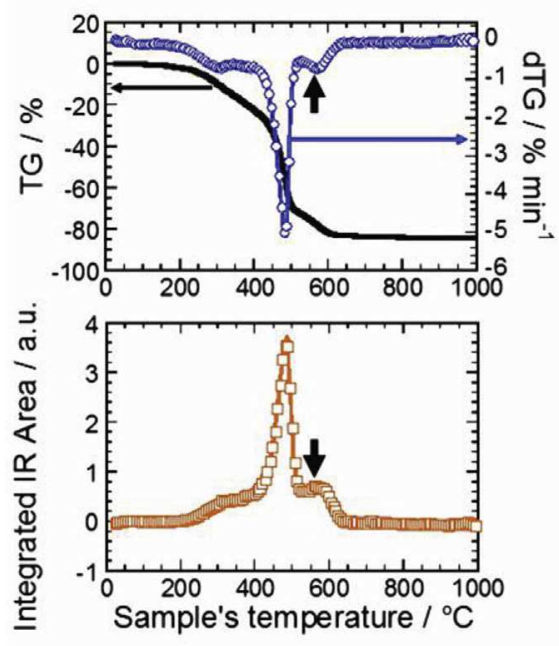

(c)

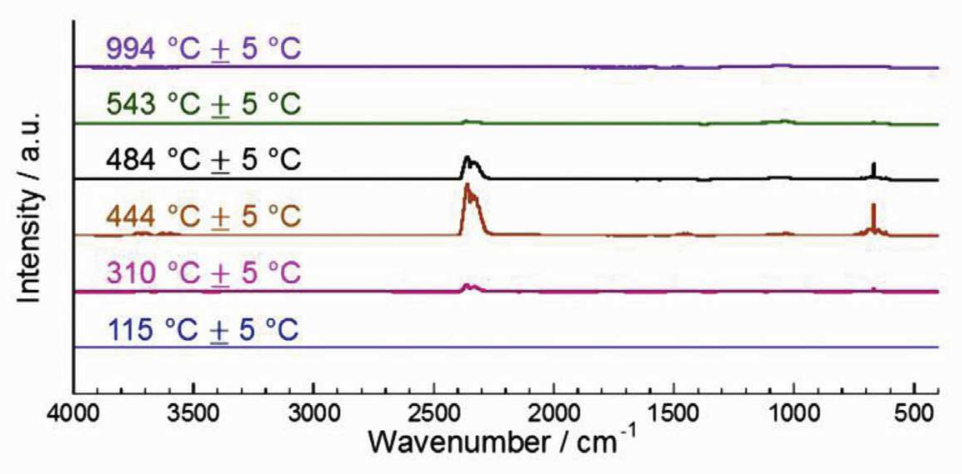

(b)

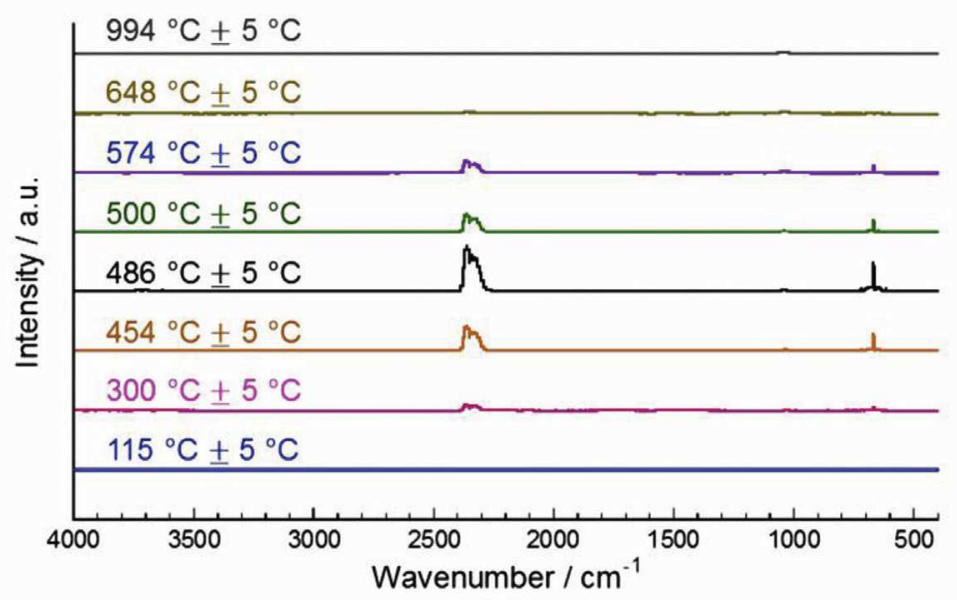

(d)

Fig. 4. Results of TGA and Infrared analysis (a) SC A's positive electrode: TG, dTG, and Integrated Infrared $\mathrm{CO}_{2}$ Peak Area versus temperature; (b) SC A's positive electrode: infrared spectra of the gasses evolved at different temperatures during TGA, where gas is released after sample reacted with oxygen; (c) SC B's positive electrode: TG and dTG versus temperature; (d) SC B's positive electrode: infrared spectra of the gasses evolved at different temperatures during TGA. 


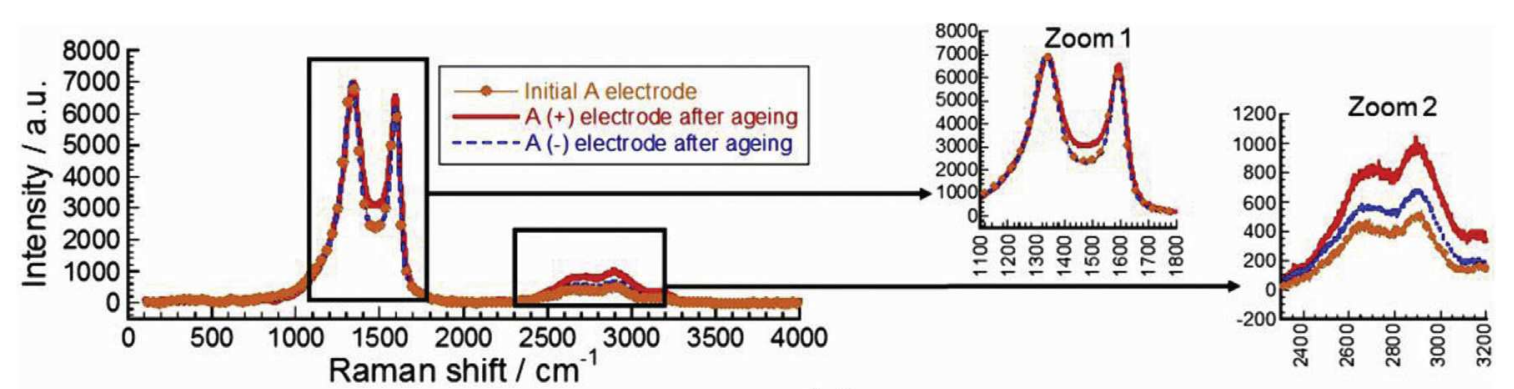

(a)

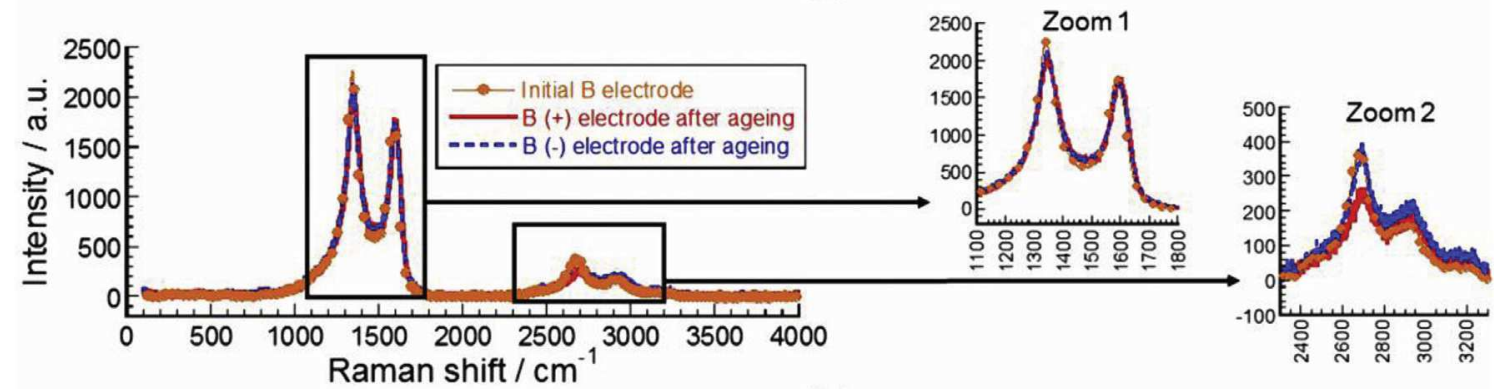

(b)

Fig. 5. Results of Raman spectroscopy: (a) comparison of initial SC A electrode with its aged positive and negative electrodes; (b) comparison of initial SC B electrode with its aged positive and negative electrodes.

degradation is less evident than that seen in SC A.

The results of the TG-IR and Raman spectroscopy analysis indicate that SC A suffered more ageing than SC B, so it is surprising that nitrogen gas adsorption/desorption analysis show results that may seem contradictory to previous results. For SC A, the plot of volume versus pore width shows a gradual decrease with ageing (Supplementary information, Fig. A.5), while SC B's volume plot versus pore width is totally flattened after ageing (Supplementary information, Fig. A.6). Ishimoto et al. [26] have studied the ageing mechanisms of carbon -based supercapacitors at high voltage in propylene carbonate-based electrolytes. Their results also agree with the formation of a SEI-like layer onto carbon particles during calendar ageing at high voltage ( $>3 \mathrm{~V}$ ). Verma et al. [27] have shown that the presence of defects on the carbon graphite surface led to the formation of inhomogeneous SEI film on negative electrode of Li-ion batteries that greatly affects the SEI properties (passivation). Defects can be edges and surface imperfections like defects, crevices, and active sites act as catalytic sites which can be active for solvent redox reaction. The combination of electrochemistry, Raman and TGA-IR analysis have shown that carbon A structure was greatly affected by ageing, resulting in an important increase in surface defects. Those highly reactive defects could form insulating islands on the carbon surface, thus blocking the surface area and leading to a resistance increase and a capacitance decrease. On the other hand, the less defective carbon SC B structure obtained after ageing could explain the formation of a protective, ionically conducting film on the activated carbon of SC B during ageing $[10,26]$. Such a film is assumed to come from the oxidation of the electrolyte at the positive electrode. The presence of this layer increases the resistance of the system but does not alter the capacitance of the carbon electrodes (while blocking gas accessibility during gas sorption measurements). Although the origin of the difference in ageing mechanism of the two carbons is still unclear, the difference in isoelectric point ( $\mathrm{pH}=7.8$ for SC $\mathrm{A}$ and 8.5 for SC $\mathrm{B}$ ), ash content ( $10 \%$ for SC B vs $<1 \%$ for SCA) or in surface groups (same content of basic surface groups but three times more acidic function groups for SC B) are thought to play an important role; this is currently under investigation.

Finally, this work shows that the combination of electrochemical techniques together with Raman and TGA-IR characterizations offers interesting perspectives for studying the ageing mechanism of activated carbons used in supercapacitor electrodes.

\section{Conclusions and outlooks}

The ageing mechanisms of two supercapacitors assembled with two different carbons are presented here. From electrochemical characterization, the ageing of the first supercapacitor (activated carbon A) is slow and continuous, with decreases in capacitance and increases in the resistance happening throughout the ageing process. In contrast, for SC B (activated carbon B) the capacitance stays stable during ageing, and only the internal resistance begins to increase drastically from the $45^{\text {th }}$ ageing cycle. Details drew from EIS, GC and Diffusion Coefficient analysis help with the establishment of two hypotheses: SC A suffered a normal ageing process with continuous material modification throughout the ageing process; while for SC B system, instead, the formation of a passive layer, which was ionically conductive and electronically resistive, occurred during ageing.

These hypotheses were confirmed by different material characterization techniques: according to TG-IR and Raman spectroscopy, SC A suffered more significant changes in its active material than SC B, where more disorder was created in SC A. The decrease of the specific surface area of carbon $B$ is consistent with the hypothesis that a passive layer is formed on the carbon $B$ after ageing.

Additionally, we can see that activated carbon A can have three kinds of defects that were generated during ageing: decreases in the sizes of nanocrystallite $\mathrm{sp}^{2}$ carbon, point defects in the $\mathrm{sp}^{2}$ carbon lattice, and the possibility that the creation of $\mathrm{sp}^{3}$ site led to the generation of $\mathrm{O}, \mathrm{F}$, and $\mathrm{H}$ functionalities on the carbon surface. The origin of these functionalities should be due to chemical attack by HF (Supplementary information, Fig. A.7), possibly produced by the hydrolysis of $\mathrm{BF}_{4}^{-}$anions [25].

For future studies, attention should be concentrated on 
modifications of the electrolytes that occur during the ageing process. In the meantime, effort can be put into isolating and analyzing the gaseous species that are generated during ageing. If the knowledge obtained such studies was used in combination with the results of this study, a complete picture of the ageing mechanisms of these types of supercapacitors could be obtained.

\section{Acknowledgement}

We thank P. Alphonse (CIRIMAT) for help with TG-IR analysis and discussion. We also thank O. Marsan (CIRIMAT) for helps of the Raman spectroscopy measurements and P. Puech (CEMES) for discussion of the Raman results. P. Simon and P.-L. Taberna thanks the Renault Company for funding. Y. Liu is supported by a grant from the Renault Company (CIFRE $N^{\circ}$ 2014/0557).

\section{References}

[1] J.R. Miller, P. Simon, Electrochemical capacitors for energy management, Science 321 (2008) 651-652.

[2] P. Simon, Y. Gogotsi, Materials for electrochemical capacitors, Nat. Mater 7 (2008) 845-854.

[3] Y. Gogotsi, P. Simon, True performance metrics in electrochemical energy storage, Science 334 (2011) 917-918.

[4] R. Kötz, M. Carlen, Principles and applications of electrochemical capacitors, Electrochimica. Acta 45 (2000) 2483-2498.

[5] B.E. Conway, V. Birss, J. Wojtowicz, The role and utilization of pseudocapacitance for energy storage by supercapacitors, J. Power Sources 66 (1997) 1-14.

[6] T. Brousse, et al, Long-term cycling behavior of asymmetric activated carbon/ MnO2 aqueous electrochemical supercapacitor, J. Power Sources 173 (2007)
633-641.

[7] J.W. Long, D. Bélanger, T. Brousse, W. Sugimoto, M.B. Sassin, O. Crosnier, Asymmetric electrochemical capacitors-stretching the limits of aqueous electrolytes, MRS Bull. 36 (2011) 513-522.

[8] L. Demarconnay, E. Raymundo-Piñero, F. Béguin, Adjustment of electrodes potential window in an asymmetric carbon/MnO2 supercapacitor, J. Power Sources 196 (2011) 580-586.

[9] J. Chmiola, C. Largeot, P.-L. Taberna, P. Simon, Y. Gogotsi, Desolvation of ions in subnanometer pores and its effect on capacitance and double-layer theory, Angew. Chem. 120 (2008) 3440-3443.

[10] P. Azaïs, et al., Causes of supercapacitors ageing in organic electrolyte, J. Power Sources 171 (2007) 1046-1053.

[11] M. Zhu, et al., Chemical and electrochemical ageing of carbon materials used in supercapacitor electrodes, Carbon 46 (2008) 1829-1840.

[12] A.M. Bittner, et al., Ageing of electrochemical double layer capacitors, J. Power Sources 203 (2012) 262-273.

[13] P. Kurzweil, M. Chwistek, Electrochemical stability of organic electrolytes in supercapacitors: spectroscopy and gas analysis of decomposition products, J. Power Sources 176 (2008) 555-567.

[18] A. Yoshida, I. Tanahashi, A. Nishino, Effect of concentration of surface acidic functional groups on electric double-layer properties of activated carbon fibers, Carbon 28 (1990) 611-615.

[21] W. Weppner, R.A. Huggins, Determination of the kinetic parameters of mixed conducting electrodes and application to the system Li3Sb, J. Electrochem. Soc. 124 (1977) 1569-1578.

[22] C. Portet, P.L Taberna, P. Simon, C. Laberty-Robert, Modification of Al current collector surface by sol-gel deposit for carbon-carbon supercapacitor applications, Electrochimica. Acta 49 (2004) 905-912.

[23] R. Beams, L.G. Cançado, L. Novotny, Raman characterization of defects and dopants in graphene, J. Phys. Condens. Matter 27 (2015) 083002.

[24] L.G. Cançado, et al., Quantifying defects in graphene via raman spectroscopy at different excitation energies, Nano Lett. 11 (2011) 3190-3196.

[25] O. Borodin, T.R. Jow, Quantum chemistry studies of the oxidative stability of carbonate, sulfone and sulfonate-based electrolytes doped with BF4 -, pf6anions, ECS Trans. 33 (2011) 77-84.

[26] S. Ishimoto, Y. Asakawa, M. Shinya, K. Naoi, Degradation responses of activated-carbon-based EDLCs for higher voltage operation and their factors, J. Electrochem. Soc. 156 (2009) A563-A571.

[27] P. Verma, P. Maire, P. Novák, A review of the features and analyses of the solid electrolyte interphase in Li-ion batteries, Electrochimica. Acta 55 (2010) 6332-6341. 